\title{
Testing the Electronic Personal Health Record Acceptance Model by Nurses for Managing Their Own Health
}

\section{A Cross-sectional Survey}

K. Gartrell' ${ }^{1}$ A.M. Trinkoff2; C.L. Storr'; M.L. Wilson ${ }^{3} ;$ A.P. Gurses ${ }^{4}$

${ }^{1}$ National Institutes of Health/National Library of Medicine/Lister Hill National Center for Biomedical Communications, Bethesda, MD; ${ }^{2}$ University of Maryland School of Nursing, Baltimore, MD; ${ }^{3}$ Johns Hopkins University School of Nursing, Baltimore, MD; ${ }^{4}$ Armstrong Institute for Patient Safety and Quality, Johns Hopkins School of Medicine, Baltimore, MD

\section{Keywords}

Personal health record, nurse, data privacy and security, health promotion, technology acceptance model

\section{Summary}

Background: To our knowledge, no evidence is available on health care professionals' use of electronic personal health records (ePHRs) for their health management. We therefore focused on nurses' personal use of ePHRs using a modified technology acceptance model.

Objectives: To examine (1) the psychometric properties of the ePHR acceptance model, (2) the associations of perceived usefulness, ease of use, data privacy and security protection, and perception of self as health-promoting role models to nurses' own ePHR use, and (3) the moderating influences of age, chronic illness and medication use, and providers' use of electronic health record (EHRs) on the associations between the ePHR acceptance constructs and ePHR use.

Methods: A convenience sample of registered nurses, those working in one of 12 hospitals in the Maryland and Washington, DC areas and members of the nursing informatics community (AMIA and HIMSS), were invited to respond to an anonymous online survey; 847 responded. Multiple logistic regression identified associations between the model constructs and ePHR use, and the moderating effect.

Results: Overall, ePHRs were used by $47 \%$. Sufficient reliability for all scales was found. Three constructs were significantly related to nurses' own ePHR use after adjusting for covariates: usefulness, data privacy and security protection, and health-promoting role model. Nurses with providers that used EHRs who perceived a higher level of data privacy and security protection had greater odds of ePHR use than those whose providers did not use EHRs. Older nurses with a higher self-perception as health-promoting role models had greater odds of ePHR use than younger nurses.

Conclusions: Nurses who use ePHRs for their personal health might promote adoption by the general public by serving as health-promoting role models. They can contribute to improvements in patient education and ePHR design, and serve as crucial resources when working with their individual patients. 


\section{Correspondence to:}

Kyungsook Gartrell, RN, PhD, NIH/NLM/LHC post-doctoral fellow

National Institutes of Health

Building 10, Room 6-2551

10 Center Drive, MSC 1504

Bethesda, MD, 20892

Tel.: 301-827-1271

Email: kyungsook.gartrell@nih.gov
Appl Clin Inform 2015; 6: 224-247

http://dx.doi.org/10.4338/ACI-2014-11-RA-0107

received: November 20, 2014

accepted: February 24, 2015

published: April 8, 2015

Citation: Gartrell K, Trinkoff AM, Storr CL, Wilson ML, Gurses AP. Testing the electronic personal health record acceptance model by nurses for managing their own health: A cross-sectional survey. Appl Clin Inf 2015; 6: 224-247

http://dx.doi.org/10.4338/ACI-2014-11-RA-0107 


\section{Introduction}

The U.S. government's Health Information and Technology (HIT) for Economic and Clinical Health Act [1] supports the adoption and meaningful use of HIT and provides incentives for providers and hospitals to demonstrate "meaningful use" of electronic health records (EHRs), including allowing patients to access their health information via an ePHR [2, 3]. An ePHR is "an electronic record of health-related information on an individual that conforms to nationally recognized interoperability standards that can be drawn from multiple sources while being managed, shared, and controlled by the individual" [4, p. 19]. ePHRs can be either non-tethered or tethered [5]. Non-tethered ePHRs are stored off line (e.g., USB drive) or on a server that is maintained by a third party (e.g., Microsoft HealthVault) [6]. Tethered ePHRs (e.g., patient portals) are connected to EHRs offered by providers, hospitals, or health insurance companies $[7,8]$. Tethered ePHRs allow patients to see selected data stored in their providers' EHR [7, 8].

The impact of ePHRs on health outcomes has been found to be equivocal yet access to health records appears to enhance a patients' perceptions of control [9]. A well-designed ePHR can educate patients on specific health problems [10], help provide health management guidelines (e.g., monitoring and adherence to treatment) and evidence-based preventive care [11-14], and track changes in health behaviors $[11,15]$, such as alcohol and drug use, regular exercise, diet, and medication compliance [16-18]. The potential for ePHRs to improve health care is significant. The ability to view and verify one's information is advantageous for chronic disease management (e.g., diabetes, heart failure, or multiple sclerosis). Studies find that using an ePHR can improve diabetes self-management and increase medication compliance [19-24]. Patients' attitudes toward ePHRs adoption has been found to be related to perceived usefulness and perceived ease of use [25], communication with providers [26-29], and ability of accessing services and information [30-32]. Providers generally report improved efficiency in treatment, interaction with patients and their family, emergency access for patients' care, and efficiency of medication management [29-31, 33-36]. Despite their potential for positive health outcomes, the prevalent barriers for ePHR adoption for both patients and providers are data privacy and security concerns $[37,38]$ as well as the accuracy of underlying data [39]. Data errors can occur when patients enter or update data in web-based ePHRs [7, 36], however certain design features (e.g., color coding or criteria-defined radio buttons) can improve data accuracy by guiding data entry [40]. Also, patients can review and verify their information in the Tethered ePHRs and alert their providers of discrepancies resulting from outdated laboratory results and medication lists [39]. Another barrier for adoption of ePHRs by patients is low computer competency and health literacy $[16,41,42]$.

Based on results of a national survey in 2010 indicating that only $10 \%$ of consumers use ePHRs [43], understanding the barriers and facilitators to adoption is critical. More research is needed to understand factors that influence ePHRs use, as definitions and types of ePHRs continue to evolve. To our knowledge, no evidence is available on health care professionals' use of ePHRs for their own health management. In this study we focus on nurses' personal use of ePHRs because a role of a nurse is to assist and encourage people to be more proactive in their own health care including personal health data record-keeping and this is the first step in establishing effective partnerships between patients and nurses [17]. Nurses have a tremendous opportunity to assist and educate patients in using ePHRs to obtain more efficient care and improved clinical outcomes [10, 44].

\subsection{Expanded Technology Acceptance Model: ePHR Acceptance Model}

This study was guided by a well-known conceptual model, the technology acceptance model [45]. The technology acceptance model has widespread application in explaining health care professionals' intention to adopt HITs [46]. Studies have shown that perceived usefulness [47-52] and perceived ease of use [53-56] are two of the most significant predictors for intention to use and actual use. The notion of the perceived usefulness and perceived ease of use in the technology acceptance model are similar to the constructs of Rogers' [57] perceived relative advantage and perceived complexity in the diffusion of innovation theory [58].

For this study, the technology acceptance model was expanded to include two additional constructs: 
1. perceived data privacy and security protection; and

2. perceived health-promoting role model (see ePHR acceptance model, $>$ Figure 1).

The Health Insurance Portability and Accountability Act and increased awareness of personal health information breaches have identified the necessity of data safeguards. Data privacy and security are perceived as barriers to adoption of ePHR among consumers [59] and physicians in clinical practice $[29,36]$. The other construct added was perceived health-promoting role model, based on the notion that nurses promote self-care and active participation of individuals in managing their health care $[60,61]$. The health-promoting role of nurses is an important factor in promoting a healthy lifestyle of patients based on nurses' experiences [60, 61].

The ePHR acceptance model also allows for moderating influences on the associations between the ePHR acceptance constructs and ePHR use. A large proportion of the U.S. nursing workforce is older than age 50 [62], thus we explored whether there is a "digital divide" [63] based on age that may influence the association between acceptance and ePHR use. Patients with chronic conditions who need more monitoring of their health and greater provider interaction might also have a different pattern of acceptance and ePHR use. One study found that more than half (56\%) of their respondents managing chronic conditions reported searching for information about their conditions or medications using ePHR [64]. While there are no data on nurses, physicians who use EHRs for patients care had a greater awareness of ePHR than physicians who had no intention of using EHRs [33]. Thus, we explored possible moderation influences of chronic illness and medication use and whether one's provider uses an EHR.

\subsection{Study Objectives}

The objectives of this study were threefold:

1. to examine the psychometric properties of the ePHR acceptance model,

2. to examine the associations of perceived usefulness, ease of use, data privacy and security protection, and perception of self as health-promoting role models to nurses' own ePHR use, and

3. to examine the moderating influences of age, chronic illness and medication use, and providers' use of EHR on the associations between the ePHR acceptance constructs and ePHR use.

We tested the following hypotheses: (H1) perceived usefulness will be positively associated with ePHR use in nurses, (H2) perceived ease of use will be positively associated with nurses' ePHR use for their own health information, $(\mathrm{H} 3)$ perceived data privacy and security protection will be positively associated with ePHR use, (H4) perceived health-promoting role model will be positively associated with ePHR use, and (H5) moderating influences of age, chronic illness and medication use, and provider's use of EHR will be seen between each of the four model constructs and ePHR use.

\section{Methods}

\subsection{Research Design and Sample}

The proposed model was tested using data from a cross-sectional, anonymous online survey of personal ePHR use among a convenience sample of U.S. registered nurses (RNs). The survey was conducted from October 2013 to January 2014. The study recruited nurses working in 12 hospitals in the Maryland and Washington, DC areas, and members in two national specialty organizations: The American Medical Informatics Association (AMIA) and the Healthcare Information and Management Systems Society (HIMSS). The accessible population included subjects 18 years or older of either gender who were able to read English and were listed under the hospital, AMIA, or HIMSS listservs. All RNs were employed at the time of the survey; retired and unemployed nurses (including students) were excluded.

RNs were informed about the survey through their respective listservs. An assumption was made that invitation e-mails and follow-up reminders were received by all the targeted nurses. The invitation e-mail and follow-up reminders included a voluntary consent, a description of the anonymity 
protection provided, and an online survey (Qualtrics@) link. The 37-item survey took approximately 15 minutes to complete. Of the 15,383 estimated RNs contacted, 847 completed a survey (estimated 5.5\% response rate). Two participants received iPad minis from a drawing offered as an incentive to encourage participation.

\subsection{Survey Development}

Reliable and validated measurement scales were chosen after a review of the literature and identifying items used in national consumer surveys. Most items required modification to reflect the context of ePHR and nursing. Four experts in methodology and informatics and four doctoral nursing students took part in the pilot testing. Their feedback was used to validate whether the study survey assessed what it was designed to measure and was useful in improving the content, skip patterns, and enhancing the clarity of the questions, such as producing consistency in the wording of items.

A description of ePHR was presented in the beginning of the survey with an ePHR screen image. The definition of ePHR was inclusive without distinguishing types of ePHR (i.e., tethered or non-tethered). For this study, ePHR users and nonusers were defined based on a yes/no response for the question, "Have you ever used an ePHR to view, update, or manage your health information?" This question was adapted from the national consumer survey on HIT conducted by the California Health Care Foundation [65]. For ePHR users, we inquired about frequency and duration of ePHR use, using questions adapted from the health information technology evaluation collaborative consumer HIT survey of Patel et al. [66].

\subsection{Measures}

Our ePHR acceptance model constructs were measured by 30 items using 4-point Likert responses that were then converted into summative scales. Greater details of the operationalization of these constructs are presented in $>$ Table 1 . Several of the constructs were tailored to appropriately denote ePHR use versus nonuse.

Based on the original definition by Davis [45], perceived usefulness was defined as the degree to which an individual believes that using an ePHR would improve their ability to manage their disease. Perceived usefulness of ePHR was assessed by 10 items taken from the national consumer survey on HIT conducted by the California Health Care Foundation [65]. The items were phrased, for ePHR users: "here are some useful ePHR features. How useful has each of these been to you?" and for ePHR nonusers: "if your health information were available on ePHR, how useful would these be to you?" Item reponses were coded as: $1=$ not at all useful, $2=$ not too useful, $3=$ somewhat useful, and $4=$ very useful. A total score was calculated by summing the individual item responses. Higher scores reflected a greater level of perceived usefulness. The Cronbach's alpha for our scale was very good at 0.89 ( $>$ Table 2).

Perceived ease of use was defined as the degree to which an individual believes that using an ePHR would be effortless based on the original definition by Davis [45]. Perceived ease of use of ePHR was measured using 4 out of 6 items of the perceived ease of use scale developed by Davis [45] (Cronbach's $\alpha=0.89-0.97$ ). The items were phrased, for users: "since you have used an ePHR, how much do you agree or disagree with each one?" and for nonusers: "if you had an ePHR, how much would you agree or disagree with each one?" Response options were coded as: 1=strongly disagree, $2=$ disagree, $3=$ =gree, and $4=$ strongly agree. A total score was calculated summing the individual item responses and a higher score meant a greater level of perceived ease of use. The Cronbach's alpha of our scale was very high at 0.95 ( Table 2); similar to the original scale of Davis [45].

Perceived data privacy and security protection was defined as the degree to which an individual believes that their ePHR contains "physical, technological, and administrative security safeguards used to protect individually identifiable health information" [67, ep. 9]. This was assessed via 8 items also used in the national consumer survey on HIT [65]. The items were phrased, for users: "how protected would you feel about the privacy and security of your information given these situations?" and for nonusers: "here are some things that might affect whether you use an ePHR that helps you view, update, or manage your health information. How protected would you feel about the privacy and security of your health information given these situations?" Responses were coded as: $1=$ not at 
all protected, $2=$ not too protected, $3=$ somewhat protected, and $4=$ very protected. A total score was calculated by summing the individual item responses and a higher score reflected a greater level of perceived data privacy and security protection (Cronbach's alpha $=0.90, \nabla$ Table 2 ).

Perceived health-promoting role model was defined as the degree to which an individual believes that "the nurse has responsibility to model personal health-promoting practices and behaviors" [61 p. 817]. Eight items were selected from the 19-item nurses' identification of self as role model of health promotion subscale within the Self as Role Model for Health Promotion scale developed by Rush and colleagues [61]. Items were phrased, "how much do you agree or disagree with each one?" with responses coded as follows: $1=$ strongly disagree, $2=$ disagree, $3=$ agree, and $4=$ strongly agree. Individual item responses were summed and a high total score represented a greater level of perceived health-promoting role model. The internal consistency reliability of our scale (Cronbach $\mathrm{a}=0.85$, see - Table 2) was better than the original scale of Rush et al. (Cronbach's $\alpha=0.49-0.71$ ) [61].

Demographic characteristics included age in years, gender, race/ethnicity, education, marital status, full-time employed status, years of working as $\mathrm{RN}$, current position, and specialty area. Health was assessed with a self-rated scale ranging from poor to excellent, which was coded as: $0=$ poor/fair, and 1=good/very good/excellent. We examined age, chronic illness and medication use, and providers' EHR use as moderators. Age was dichotomized (older: $>50$ vs. younger: $\leq 50$ ). More than one-third (41\%) of our sample was older than 50, which is similar to the result of the U.S. nursing workforce survey in 2013 [62]. Questions for chronic conditions and medication use were adapted from a consumer survey [66]. Responses from the questions for chronic condition and medication use were combined to decrease collinearity (coded as no=neither condition, and yes=either one or both). A single item assessed whether the respondent's providers used EHR as part of their own health care (yes/no).

\subsection{Analysis}

We used descriptive statistics to examine the distribution and frequency of the four constructs (perceived usefulness, ease of use, data privacy and security protection, and health-promotiong role model), age, chronic illness and medication use, providers' use of EHR, the nursing group (i.e., nursing informatics community vs. hospital nurses), and other demographic information. Differences were explored using t-tests for continuous variables and chi-square with Yate's correction for continuity, which compensates for the overestimate of the chi-square value when used with a 2 by 2 table, for categorical variables. Correlations among the four constructs were calculated using Pearson's correlation statistic. The correlations among ePHR acceptance constructs were small $(\mathrm{r}<0.30)$, positive, and significant $(\mathrm{p}<0.01)$, with the exception of the correlation between perceived ease of use and perceived data privacy and security protection as medium $(r=0.39, \mathrm{p}<0.01)$. Cronbach's alpha coefficient was used to assess the internal consistency reliability of each scale and all values were greater than the acceptance level of 0.70 [68]. Independent sample t-tests indicated evidence for construct validity [69] of each scale because significant differences were found between the mean scores of ePHR users and nonusers on perceptions of usefulness $(\mathrm{p}<0.01)$, ease of use $(\mathrm{p}<0.05)$, and health-promoting role model $(\mathrm{p}<0.05)$.

Relationships were evaluated via odds ratios estimates and the use of regression models that allowed us to test if constructs were significantly related to ePHR use. Unadjusted estimates were derived from binary logistic regression models before proceeding to models that included additional covariates. Additional covariates included nursing group (nursing informatics community vs. hospital nurses), age, chronic illness and medication use, and providers' use of EHR. Multiple logistic regression models using a forced entry method were used to examine the association of the four constructs with ePHR use and covariates. Interaction terms were then entered into models. Statistical interaction occurs when the effect of one independent variable (e.g., perceived health-promoting role model) on the ePHR use depends on the value of another independent variable (e.g., age) [70]. If the p-value of the interaction effect (e.g., perceived health-promoting role model ${ }^{*}$ age) is less than 0.05 , the interaction is significant. For covariates found to be operating as moderators, we plotted an interaction graph and calculated separate odds ratios for subgroups. No outliers (standardized residual $>3$ ) and no multicollinearity across the covariates was found. Omnibus tests were all significant $(\mathrm{p}<0.05)$ except perceived data privacy and security protection in crude odds ratios ( $\triangleright$ Table 4$)$. 
Hosmer-Lemeshow tests indicated that there was a good fit ( $\mathrm{p}>0.05)$ in all models except for perceived data privacy and security protection in crude odds ratios and in the model that adjusted for all covariates ( Table 4). SPSS ${ }^{\circledR} 21$ was used for all data analyses.

\section{Results}

\subsection{Sample Description}

The average age of the 847 nurse respondents was 45 years, ranging from 21 to 71 ( Table 3). The majority of respondents were female (95\%), white (75\%), married (68\%), and employed full-time (91\%). Nearly $80 \%$ of them worked as hospital nurses, most of them being staff nurses (61\%) in noncritical areas (64\%). The vast majority of respondents (96\%) self-rated their health status as excellent, very good, or good, although $69 \%$ indicated they had either a chronic illness or medication use. Over two thirds $(71 \%)$ had providers that used EHRs. Forty-seven percent of respondents $(n=400)$ were ePHR users, with $82 \%$ of them using ePHR less than once a month. ePHR users spent an average of 19 minutes $(\mathrm{SD}=17.4)$ each time they accessed ePHR.

Several characteristics varied by ePHR use. A larger proportion of ePHR users had a Master's degree or higher (40\%) and were currently married or living with partners (71\%) compared to nonusers, respectively $28 \%$ and $65 \%$. ePHR users were significantly less likely to be staff nurses (51\%), and to have noncritical care specialties (55\%) as compared to nonusers, respectively $69 \%$ and $71 \%$. Nurses in the ePHR user group had been working as a RN longer than nonusers (average 20 years vs. 18 years respectively). Nurses in the ePHR user group were significantly older (age $>50, p<0.05)$, had more chronic illness and medication use $(\mathrm{p}<0.01)$, had providers that used EHR in their practice $(\mathrm{p}<0.01)$, and were more likely to be a member of the nursing informatics community $(\mathrm{p}<0.01)$.

\subsection{Associations of Each Construct to Nurses ePHR use}

Each ePHR acceptance construct showed a significant association with ePHR use except perceived data privacy and security protection ( Table 4) (crude odds ratios). Perceived usefulness had a significant negative association with ePHR use, such that ePHR users were less likely to perceive the ePHR as useful compared to nonusers $(\mathrm{OR}=0.90,95 \% \mathrm{CI}=0.88-0.92)$. Significant differences were found in all features of perceived usefulness between users and nonusers $(p<0.01$, see $>$ Supplemental Figure). The vast majority of ePHR users valued all features less (i.e., somewhat useful + very useful) than nonusers. ePHR users clearly valued four features more (i.e., somewhat useful + very useful): "looking at the results of your lab tests or other tests (95\%)", "making sure your information is correct (93\%)", "sending or getting an e-mail from a doctor or nurse (88\%)", and "managing your family's health visits, medicines, and other information in one place (87\%)" than other features. Perceived ease of use was positively associated with ePHR use, as ePHR users were significantly more likely to perceive the ePHR as easy to use compared to nonusers $(\mathrm{OR}=1.05,95 \% \mathrm{CI}=1.01-1.09)$. Perceived data privacy and security protection had a positive association with ePHR use, but it was not statistically significant $(\mathrm{OR}=1.01,95 \% \mathrm{CI}=0.98-1.03)$. Perceived health-promoting role model was positively associated with ePHR use. ePHR users were significantly more likely to perceive that a health-promoting role model is important compared to nonusers ( $\mathrm{OR}=1.03,95 \% \mathrm{CI}=1.01-1.05)$. Together, all ePHR acceptance constructs made statistically significant contributions to the model that also adjusted for nursing group (model 1) and the direction remained the same as the unadjusted estimates. The amount of variance in ePHR use accounted for by all four constructs in model 1 was between 29\% (Cox\&Snell R2) and 39\% (Nagelkerke R2). Those significant contributions of ePHR acceptance constructs remained the same, except for perceived ease of use ( $\mathrm{p}$-value changed from model $1=0.03$ to model $2=0.06$ ), after including the additional covariates of age, chronic illness and medication use, and providers' use of EHR in model 2. The amount of variance in ePHR use accounted for by all four constructs in model 2 was between 33\% (Cox\&Snell R2) and 44\% (Nagelkerke R2). 


\subsection{Moderating Influence}

An interaction was detected between perceived data privacy and security protection and the providers' use of EHR $(\mathrm{p}<0.05)$ on ePHR use. Therefore, separate odds ratios for the association between ePHR use and perceived data privacy and security protection were calculated for each of the two provider subgroups. As seen in Table 5 (crude odds ratios), nurses who perceived greater data privacy and security protection had greater odds of ePHR use $(\mathrm{OR}=1.01,95 \% \mathrm{CI}=0.99-1.04)$ if their providers used EHRs than those whose providers did not use EHRs (OR=0.96, 95\% CI=0.92-1.00). The significantly different slopes of these two subgroups were plotted to demonstrate the positive interaction. Figure 2 displays the association between perceived data privacy and security protection and ePHR use by provider subgroup. The slope for the nurses whose providers did not use EHR was associated with a greater decrease in perceived data privacy and security protection scores than the slope for the nurses whose providers used EHR. These odds ratio estimates for the subgroup models adjusted for nursing group (Model 1) and for nursing group, age, and chronic illness and medication use (Model 2) were very similar to the crude estimate of the unadjusted model ( $\downarrow$ Table 5 ).

A significant interaction effect between perceived health-promoting role model and age $(\mathrm{p}<0.05)$ was also detected in relation to ePHR use and separate odds ratios were calculated for each age subgroup ( $\$$ Table 6 ). Older nurses (age $>50$ ) who perceived themselves as greater health-promoting role models had greater odds of ePHR use $(\mathrm{OR}=1.07,95 \% \mathrm{CI}=1.02-1.11)$ compared to younger nurses (age $\leq 50 ; \mathrm{OR}=1.01,95 \% \mathrm{CI}=0.98-1.04$ ). $>$ Figure 3 illustrates the association between perceived health-promoting role model and ePHR use by age groups. The slope for the older nurses was associated with a greater increase in perceived health-promoting role model scores than the slope for the younger nurses. Estimates from the adjusted models were similar to the crude estimate ( Table 6). No interactions were found for chronic illness and medication use.

\section{Discussion}

Overall, measures created for our adaptation of the technology acceptance model had sufficient internal consistency reliability and construct validity. More importantly the ePHR acceptance model fit the data well. ePHR use variance (33\%-44\%) was explained by perceptions on usefulness, ease of use, data privacy and security protection, and health promoting-role model after holding other covariates constant. Studies on nurses, physicians, and pharmacists have also found that the variance in actual use of HIT (55\%-75\%) is explained by perceptions on usefulness and ease of use [49, 50, 54]. Three constructs were significantly related to nurses' own ePHR use after adjusting all covariates: usefulness, data privacy and security protection, and perception of self as a health-promoting role model. Significant interactions were found between data privacy and security protection and the providers' use of EHR on ePHR use and between health-promoting role modelling and age on ePHR use.

Nurses who used ePHR were significantly less likely to feel that ePHR was useful for their own health management compared to nonusers, which did not support our hypothesis. This finding was contrary to previous HIT studies among health care professionals where statistically significant positive association between perceived usefulness and technology use has been found [52, 55, 56, 71, 72]. Perceived usefulness has also been found to be a significant factor that influences the use of an ePHR among patients [73, 74]. Our unexpected finding should be viewed with caution as the users' answers were based on their actual experience, while the nonusers' responses were based on perceptions. The description of ePHR that was provided in the beginning of the survey and the hypothetical prompt questions (e.g., if your health information were available on ePHR, how useful would these be to you?) might have introduce some bias. However, ePHR users clearly valued some feature over others, a finding found by other studies [74,75]. We did not assess what specific functionalities were available and users may not have access to all of the functions asked about in the survey, as one survey has found that about 35\% of their ePHR respondents answered as "have not done" when asked about specific features [65]. Alternatively, nurses in our sample may have felt that the items were not applicable because the vast majority of them were healthy and working. Increasing use of ePHR may not improve health outcomes unless patients adopt and use it consistently [66] and we 
found that the majority of users used ePHRs less than once a month. Additional research is needed to understand whether frequent users are more likely to perceive usefulness of ePHR as compared to nonfrequent users. Future research should also examine whether users' perceptions of ePHR usefulness are different based on the complexity of the ePHR.

Perceived ease of use showed a positive association with ePHR use, which supported our hypothesis. Our result, like those of others $[49,54]$, showed that nurses who used ePHR were more likely to perceive ePHR as easy to use. Perceived ease of use was the facilitator for adoption of ePHRs by family physicians [29] and patients [31,73]. We did not examine the relationship between perceived usefulness and ease of use; studies find perceived ease of use to be a significant antecedent of perceived usefulness among nurses and occupational therapists that adopt HITs [54, 55, 76, 77]. Future research should examine the association between perceived usefulness and ease of use.

Although perceived data privacy and security protection did not show a significant bivariate association with ePHR use, it was significantly associated with ePHR use after adjustment for covariates. Nurses in ePHR user group were more likely to feel that their data and privacy were protected in their ePHRs compared to nonusers after adjustment for covariates. Similar to our finding, ePHR users among consumers were less concerned about the privacy of information in their ePHRs [59]. Perceived privacy concern was a potential risk factor for willingness to use ePHRs by both providers and patients $[29,36,78]$. Similarly, privacy and security concerns were barriers to the adoption of HIT by a family medicine group [79]. Angst and Agarwal [78] found that privacy concerns were negatively associated with the likelihood of adoption of ePHR among the general population. Tung et al. [77] found that perceived ease of use has direct and positive influence on trust, which, in turn, has a direct and positive influence on perceived usefulness when nurses adopt a HIT. These directions were not included in our model but should be tested in future research.

Perceived health-promoting role model was hypothesized to have a positive association with ePHR use. An important new finding is that nurses in the ePHR user group were more likely to perceive themselves as health-promoting role models than nonusers. Awareness of one's own fitness and lifestyle behaviors is a basis of health promotion for nurses $[60,61,80]$, and nurses generally perceived health promotion as part of their role [81]. A champion (e.g., an advocate for the use of an ePHR) can play the role of knowledge agent by transferring information they gained from experiences into the implementation processes [79, 82]. Nursing feedback and involvement in design, development, and implementation of HIT were found to be critical in improving quality of care [83-85]. Nurses' health-promoting role can enhance patients' preventive care (e.g., promoting a healthy diet and excise, smoking cessation, age appropriate screening, chronic disease management and medication compliance, or other hygiene practices) [81]. Nurses can act as role models, encouraging and motivating patients to learn about their health and take ownership of the decisions and behaviors that ultimately affect their health. Thus, personal experience with their own ePHR use may encourage nurses to promote use among patients. Indeed, the Office of the National Coordinator for Health Information Technology and the American Nurses Association supports a professional obligation to become familiar with the technology and promote personal health care information management [86]. Nurses' health promoting role can advance patient education in ePHRs for more efficient care and improved clinical outcomes.

Our hypotheses that the providers' use of EHR acts as a moderator between perceived data privacy and security protection and ePHR use and that nurses' age acts as a moderator between perceived health-promoting role and ePHR use were both supported. It may be that tethered ePHRs offer significantly more features and values (e.g., access to their medical record data). Patients have reported feeling trust and confidence in their providers by accessing their information that was stored in EHRs $[87,88]$. More than half $(54 \%)$ of physicians adopted EHRs in 2011 and $74 \%$ of adopters reported believing that patient care is enhanced by using EHRs [89]. Our findings suggest that the use of EHR by providers is a great resource for patients to be aware of ePHR [89] because physicians commonly offer ePHRs to patients [43]. This may allow individuals to have a sense of control over their privacy and confidentially in ePHRs [90]. Age has been found to moderate HIT adoption in another study [91]. Older nurses (age>50) in our study were more likely to perceive themselves as health-promoting role models than younger nurses (age $\leq 50$ ), which influenced use of ePHR. The higher perceptions on health-promoting role among older nurses is very encouraging for the use of ePHR. 


\section{Limitations}

Initial inquiries into new areas of research often have sampling and design limitations and this study is no exception. One weakness of a survey is that causal relationship cannot be inferred; only associations can be established [92]. In addition, restraint should be used in generalizing the findings because of the convenience sampling method and the extremely low response rate. While more than one-third (41\%) of our sample was older than 50, comparable to proportions found in the most recent U.S. workforce nurse survey [62], there may be other sampling biases as it is possible that nurses who are technologically savvy and have interests in the topic of ePHRs might be more likely to participate in a survey like ours. Thus our estimates should be viewed with caution and it remains to be seen whether the association between factors remains the same if the sample composition is different.

The survey also had some limitations in the context of measurement. We did not distinguish what type of ePHR (tethered or non-tethered) participants used, which could explain whether ePHR use is influenced by the features of the ePHR (e.g., usefulness). This study evaluated ePHR acceptance constructs using self-reported perceptions as opposed to objective measures. The assessment of perceptions on usefulness, ease of use, and data privacy and security protection in ePHRs among nonusers should be cautiously interpreted because the responses from them were hypothetical, not actual. In contrast, the internal consistency reliabilities of all scales showed good Cronbach's alpha, and most previous HIT acceptance studies that employed self-reported measures demonstrated acceptable reliability in the summative scales $[45,93]$. There are variables that could further explain ePHR acceptance and use, such as peer influence, that were not explored in our study. However, this study represents a rare attempt to model nurses ePHR acceptance based on an expanded technology acceptance model that included perceived data privacy and security protection and health-promoting role. The overall models fit the data well and ePHR use variance was explained by $33 \%-44 \%$ with four constructs after controlling all covariates.

\section{Conclusions and Future Research}

This study was exploratory and innovative as no other studies have yet assessed data privacy and security protection and health-promoting role modelling in the technology acceptance model. After controlling for several covariates, perceptions of usefulness, data privacy and security protection, and health-promoting role were all statistically significant factors that influenced ePHR use. Our findings suggest that ePHR users feel more protected and less concerned about privacy and security when their providers use EHRs. Promoting wide adoption and use of ePHRs by nurses may benefit the general public by endorsing the use of ePHRs. Moreover, nurses may contribute to improvements in patient education and ePHR design.

Future surveys should strive for better response rates by improving methods to engage nonresponders while also being cognizant of obtaining representative samples of nurses. Research on this topic could also include other health care professionals (e.g., pharmacists and physicians). Our expanded model and items that measured the concepts of perceptions of usefulness, ease of use, data privacy and security protection, and health-promoting role should be replicated to confirm reliability and validity. Further assessment of different types of ePHRs may explain whether more complex ePHR features affect adoption and use of ePHR.

\section{Clinical Relevance Statement}

ePHR research often lacks a theoretical framework supported by empirical findings and to our knowledge no studies have examined health care professionals' ePHRs use for their own personal health management. More work needs to be done in this area because if health care professionals do not express satisfaction and do not want to use ePHRs for their own health monitoring how can we expect patients in general to use them? 


\section{Conflicts of Interest}

None of the authors have a conflict of interest. The authors are responsible for the writing and content of this article. The opinions expressed in this article are those of the authors and do not necessarily reflect the policies of the National Institutes of Health.

\section{Human Subjects Protections}

Neither human nor animal experimental subjects were included in the project. The study received Institutional Review Board approval from the University of Maryland, Baltimore and each facility, and permission was obtained from AMIA and HIMSS.

\section{Acknowledgments}

This work was supported by the American Nursing Informatics Association Scholarship Award and by the Graduate Assistance in Areas of National Need fellowship from the University of Maryland School of Nursing. The authors would like to thank the nurses who participated in the survey. The authors also would like thank the editorial assistance of the National Institutes of Health Fellows Editorial Board. 


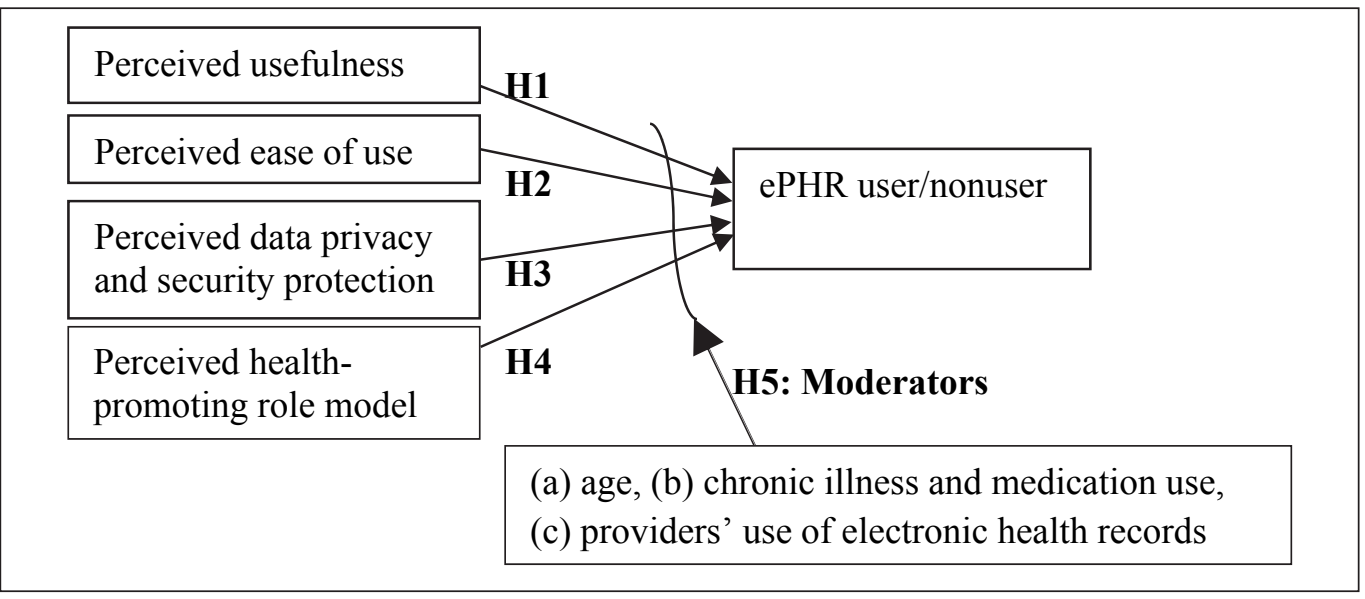

Fig. 1 Electronic Personal Health Record (ePHR) Acceptance Model among Nurses (adapted from the Technology Acceptance Model of Davis, 1989). The ePHR acceptance model contains four constructs on the left side and the outcome variable on the right side. The directions are illustrated with arrows for each hypothesis. The tested moderators between four constructs and the outcome variable are illustrated as one large arrow.

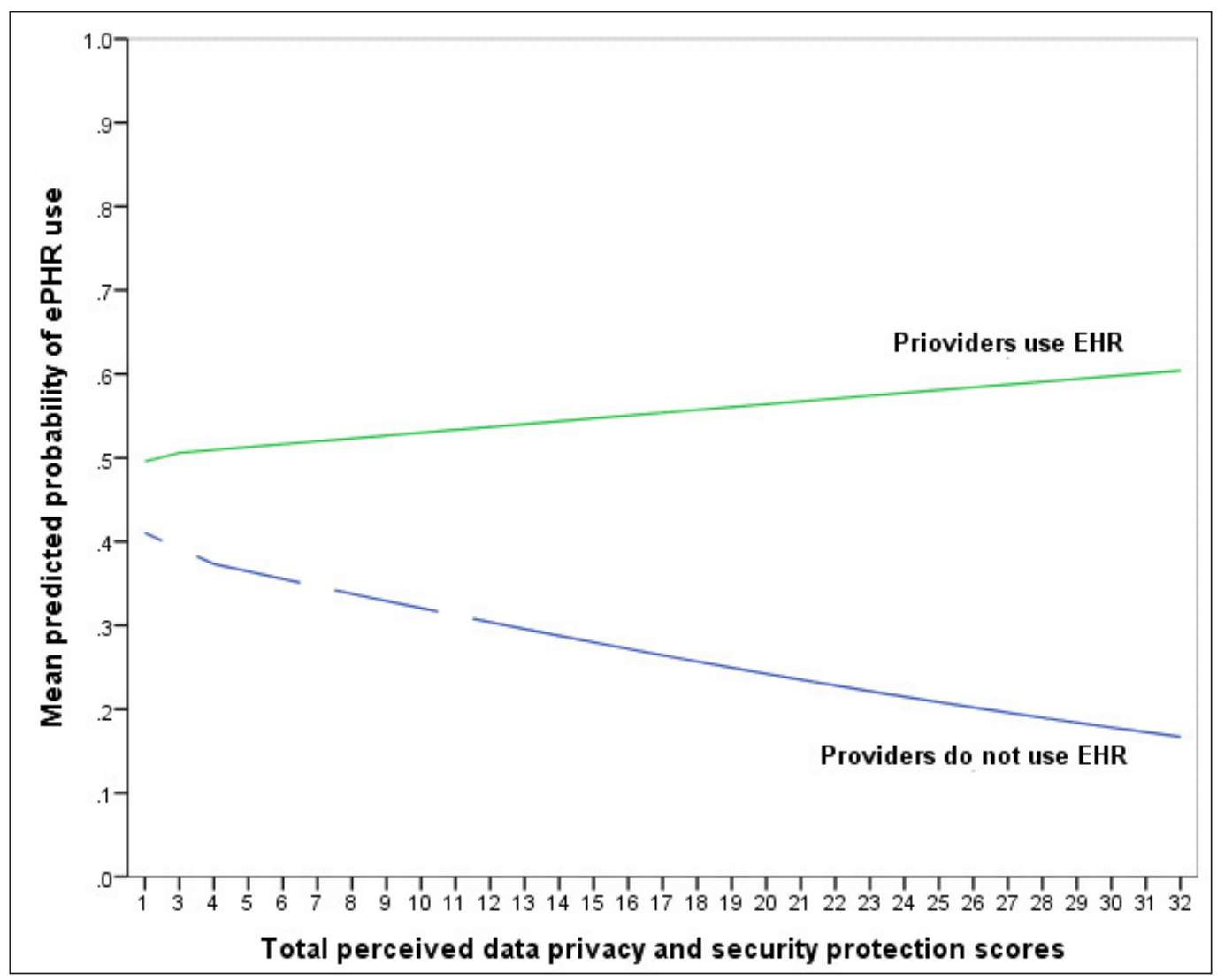

Fig. 2 Predicted Probability of ePHR Use and Perceived Data Privacy and Security Protection by Providers Use of Electronic Health Records. Lines are broken where no total scores exist. 


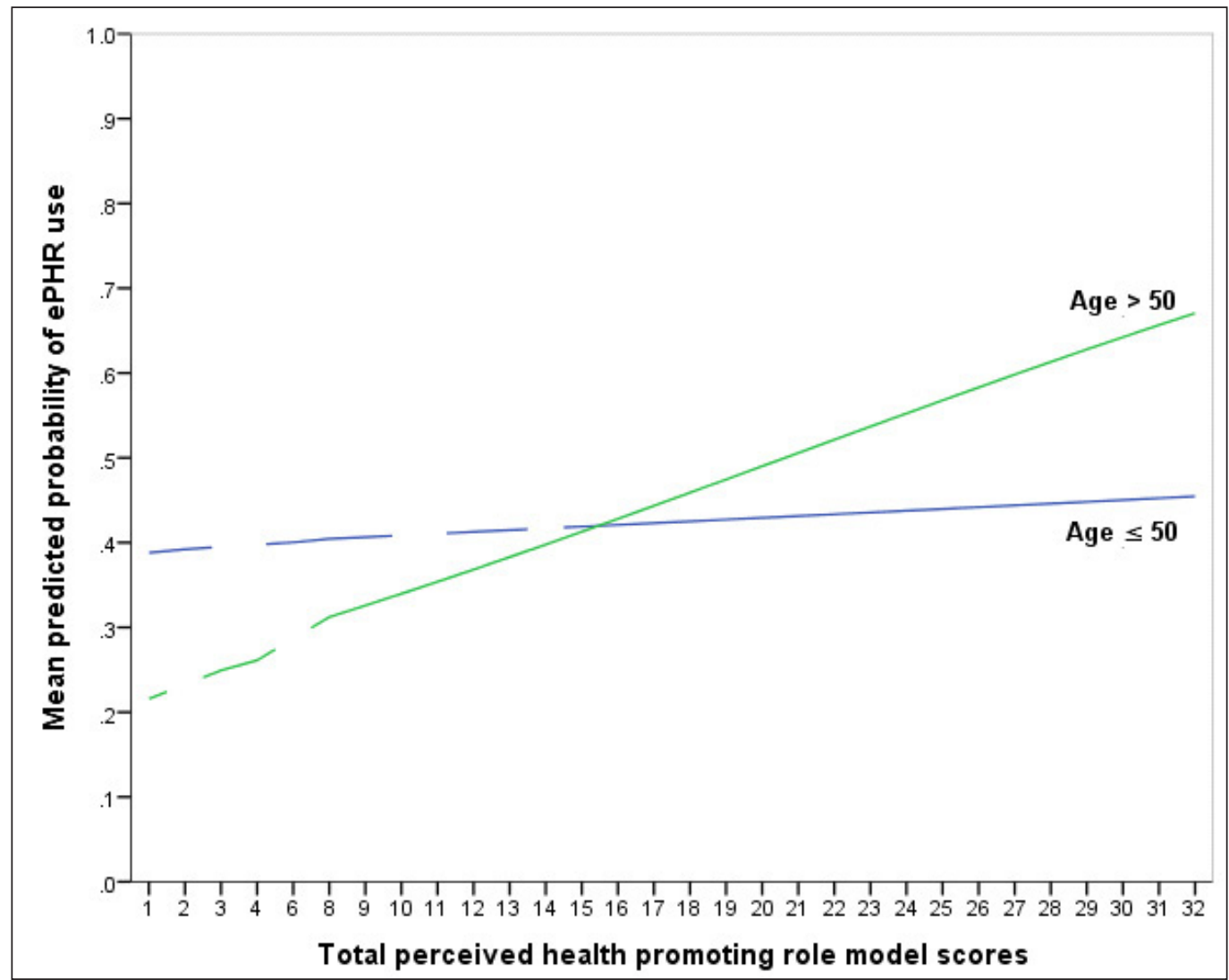

Fig. 3 Predicted Probability of ePHR Use and Perceived Health-Promoting Role Model by Age. Lines are broken where no total scores exist. 


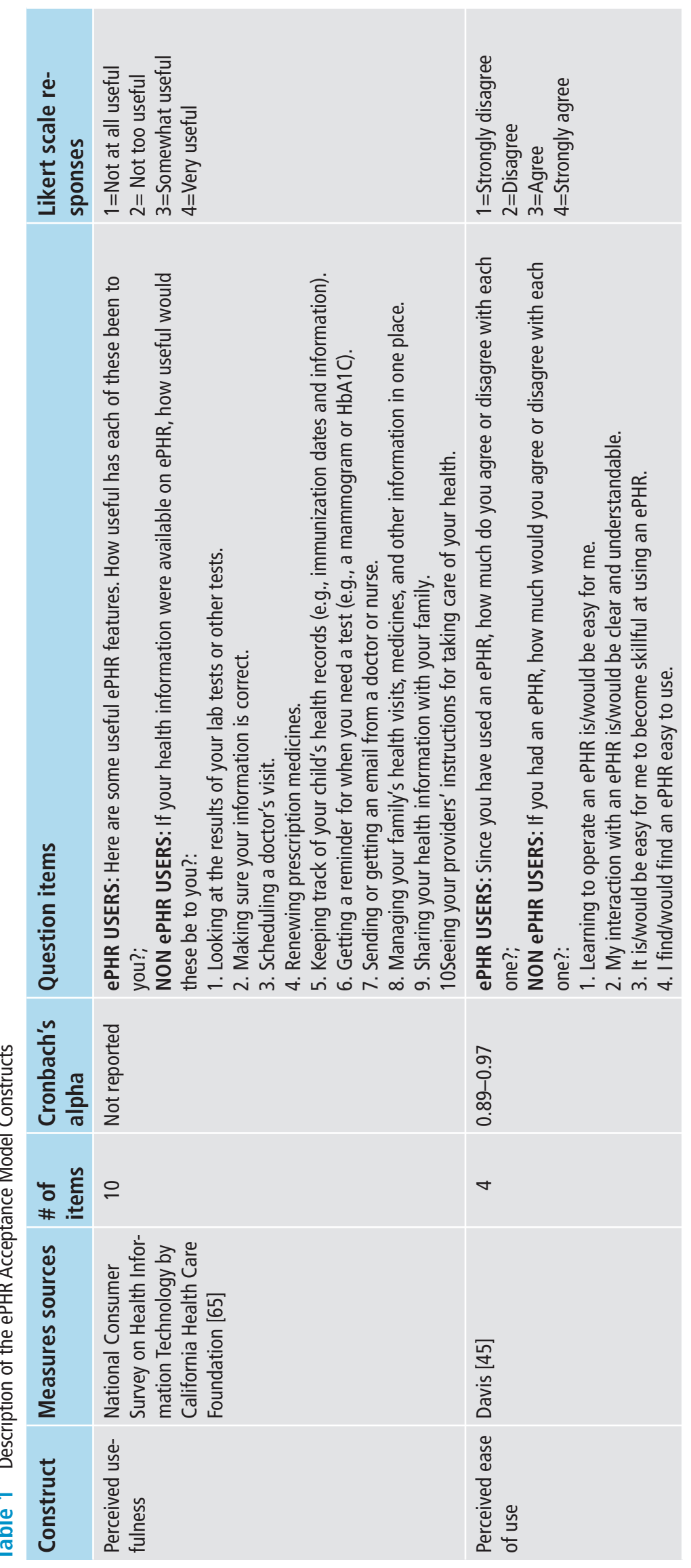




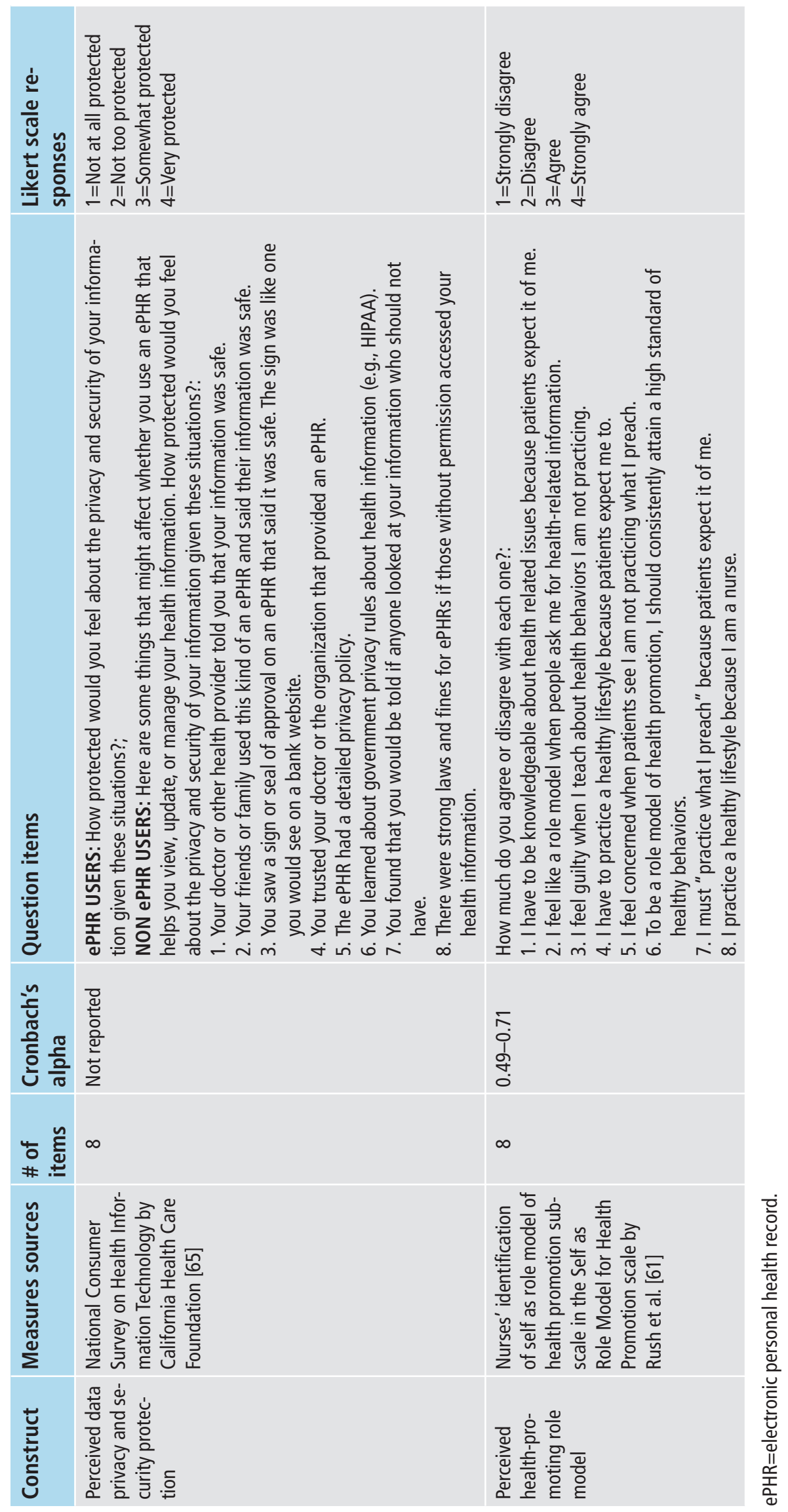




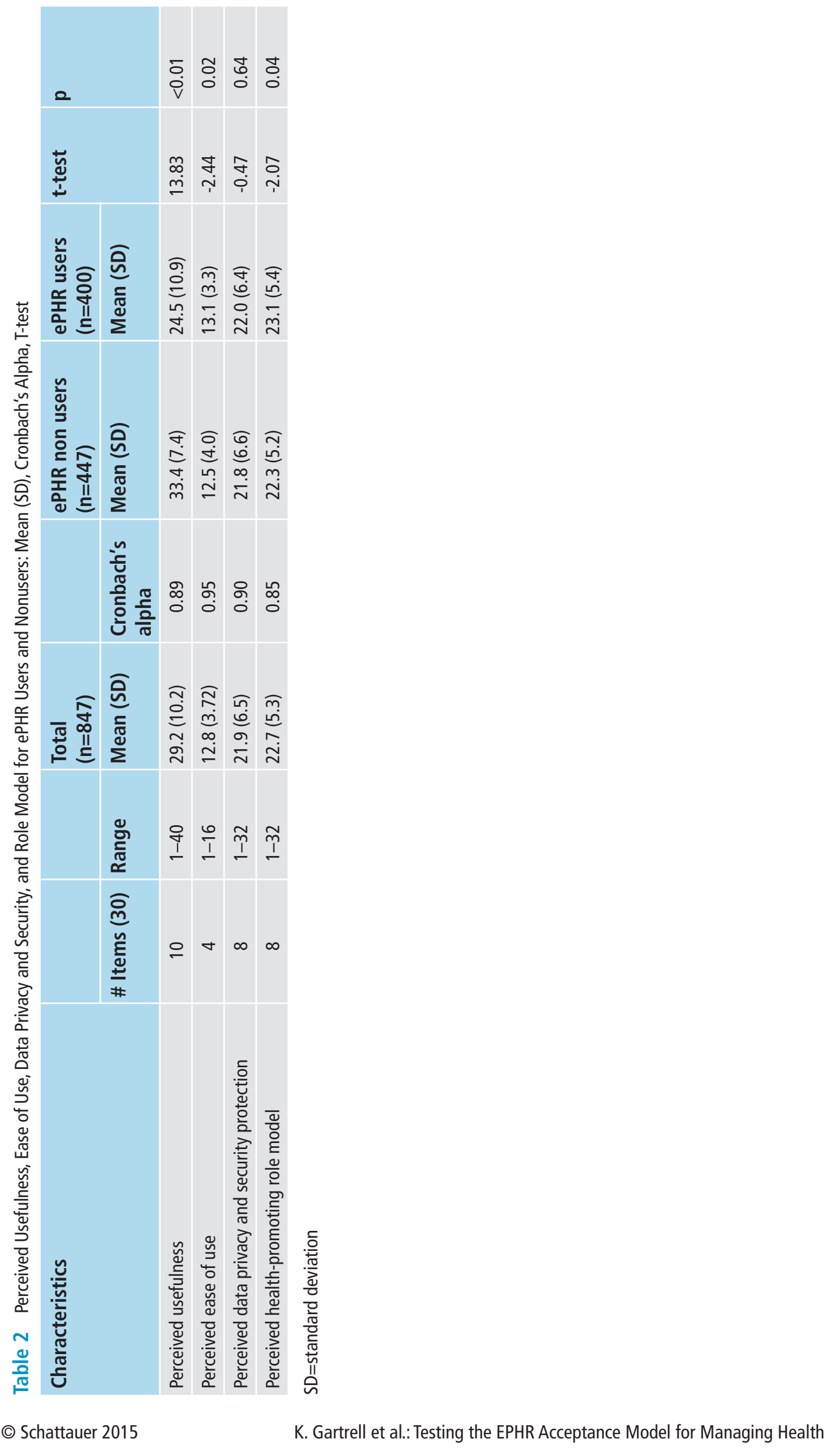


Table 3 Characteristics $(n, \%)^{a}$ of Nurses $(n=847)$

\begin{tabular}{|c|c|c|c|c|c|}
\hline Demographics & $\begin{array}{l}\text { Total } \\
(n=847)\end{array}$ & $\begin{array}{l}\text { ePHR } \\
\text { nonusers } \\
(n=447)\end{array}$ & $\begin{array}{l}\text { ePHR } \\
\text { users } \\
(n=400)\end{array}$ & $X^{2}$ & $p$ \\
\hline Age (years), Mean (SD) & $45.1(12.6)$ & $44.3(12.8)$ & $46.0(12.4)$ & $\mathrm{t}=-1.91$ & 0.06 \\
\hline$\leq 50$ & $498(59.0)$ & $281(63.0)$ & $217(54.5)$ & $6.26^{b}$ & 0.01 \\
\hline$>50$ & $346(41.0)$ & $165(37.0)$ & $181(45.5)$ & & \\
\hline Female & $799(94.6)$ & $424(95.1)$ & $375(94.0)$ & $0.29^{b}$ & 0.59 \\
\hline White & $633(75.2)$ & $321(72.6)$ & $312(78.0)$ & $2.97^{\mathrm{b}}$ & 0.09 \\
\hline \multicolumn{6}{|l|}{ Education } \\
\hline Diploma/associate's degree & $109(12.9)$ & $68(15.3)$ & $41(10.3)$ & 13.91 & $<0.01$ \\
\hline Bachelor's degree & $451(53.4)$ & $251(56.4)$ & $200(50.0)$ & & \\
\hline Master's/doctoral & $285(33.7)$ & $126(28.3)$ & $159(39.8)$ & & \\
\hline \multicolumn{6}{|l|}{ Marital status } \\
\hline Never married & $166(19.7)$ & $105(23.6)$ & $61(15.3)$ & 9.19 & $<0.05$ \\
\hline Divorced/separated/widowed & $106(12.6)$ & $53(11.9)$ & $53(13.3)$ & & \\
\hline Currently married/living with partner & $572(67.8)$ & $287(64.5)$ & $285(71.4)$ & & \\
\hline \multicolumn{6}{|l|}{ Employment status } \\
\hline Full-time employed, yes & $772(91.1)$ & $412(92.2)$ & $360(90.0)$ & $0.98^{b}$ & 0.32 \\
\hline Years of working as registered nurse, Mean (SD) & $18.9(12.9)$ & $18.0(12.7)$ & $19.9(13.0)$ & $\mathrm{t}=-2.20$ & 0.03 \\
\hline \multicolumn{6}{|l|}{ Current position } \\
\hline Staff/general duty/private duty & $515(60.8)$ & $310(69.4)$ & $205(51.3)$ & 61.18 & $<0.01$ \\
\hline Nurse manager/supervisor/other administrator & $119(14.0)$ & $58(13.0)$ & $61(15.3)$ & & \\
\hline Clinical informatics specialist $^{c}$ & $119(14.0)$ & $25(5.6)$ & $94(23.5)$ & & \\
\hline Other ${ }^{d}$ & $94(11.1)$ & $54(12.1)$ & $40(10.0)$ & & \\
\hline \multicolumn{6}{|l|}{ Specialty area } \\
\hline Noncritical care & $539(63.6)$ & $319(71.4)$ & $220(55.0)$ & 53.72 & $<0.01$ \\
\hline Critical care & $177(20.9)$ & $97(21.7)$ & $80(20.0)$ & & \\
\hline Nursing informatics & $131(15.5)$ & $31(6.9)$ & $100(25.0)$ & & \\
\hline \multicolumn{6}{|l|}{ Health } \\
\hline Poor/fair & $35(4.1)$ & $24(5.4)$ & $11(2.8)$ & $3.02^{b}$ & 0.08 \\
\hline Good/very good/excellent & $812(95.9)$ & $423(94.6)$ & $389(97.3)$ & & \\
\hline \multicolumn{6}{|l|}{ Nursing group } \\
\hline Hospital & $664(78.4)$ & 395 (88.4) & $269(67.3)$ & $54.34^{b}$ & $<0.01$ \\
\hline Nursing informatics community & $183(21.6)$ & $52(11.6)$ & $131(32.8)$ & & \\
\hline \multicolumn{6}{|l|}{ Chronic illness and medication use } \\
\hline No & $266(31.4)$ & $160(35.9)$ & $106(26.5)$ & $8.17^{b}$ & $<0.01$ \\
\hline Yes & $580(68.6)$ & $286(64.1)$ & $294(73.5)$ & & \\
\hline
\end{tabular}


Table 3 Continued

\begin{tabular}{|l|l|l|l|l|l|}
\hline Demographics & $\begin{array}{l}\text { Total } \\
(\mathbf{n = 8 4 7 )}\end{array}$ & $\begin{array}{l}\text { ePHR } \\
\text { nonusers } \\
(\mathbf{n = 4 4 7 )}\end{array}$ & $\begin{array}{l}\text { ePHR } \\
\text { users } \\
(\mathbf{n}=400)\end{array}$ & $\mathbf{X}^{2}$ & $\mathbf{p}$ \\
\hline Providers use electronic health record & & & & & \\
\hline No & $250(29.5)$ & $191(42.7)$ & $59(14.8)$ & $78.10^{b}$ & $<0.01$ \\
\hline Yes & $597(70.5)$ & $256(57.3)$ & $341(85.3)$ & & \\
\hline
\end{tabular}

ePHR=electronic personal health record. SD=standard deviation.

aPercentage may not sum to 100 because of rounding; numbers may not sum to totals due to missing responses. bYate's correction for continuity to compensates for the overestimate of the Chi-square value when used with a 2 by 2 table.

'Clinical analyst/Nursing informatics analyst/nurse informaticist/informatician/informatics nurse specialist/informatics specialist/chief nursing informatics officer/supervisor nursing informatics/nursing informatics consultant/ developer.

${ }^{\mathrm{d} N u r s e}$ practitioner/certified registered nurse anesthetist/clinical nurse specialist/certified nurse midwife/educator/ researcher

Table 4 Odds Ratios of ePHR Acceptance Constructs on ePHR Use by Nurses

\begin{tabular}{|c|c|c|c|c|c|c|}
\hline & \multicolumn{2}{|c|}{$\begin{array}{l}\text { Crude Odds Ratios } \\
\text { (OR) }(n=847)\end{array}$} & \multicolumn{2}{|c|}{ Model $1^{a}(n=847)$} & \multicolumn{2}{|c|}{ Model $2^{b}(n=844)$} \\
\hline & OR $(95 \% \mathrm{Cl})$ & $p$ & OR $(95 \% \mathrm{Cl})$ & $p$ & OR $(95 \% \mathrm{Cl})$ & $p$ \\
\hline H1: Perceived usefulness & $0.90(0.88-0.92)$ & $<0.01$ & $0.87(0.85-0.89)$ & $<0.01$ & $0.87(0.85-0.89)$ & $<0.01$ \\
\hline H2: Perceived ease of use & $1.05(1.01-1.09)$ & 0.02 & $1.06(1.01-1.12)$ & 0.03 & $1.06(1.00-1.12)$ & 0.06 \\
\hline $\begin{array}{l}\text { H3: Perceived data security } \\
\text { and privacy protection }\end{array}$ & $1.01(0.98-1.03)$ & 0.64 & $1.04(1.01-1.07)$ & 0.01 & $1.04(1.01-1.07)$ & 0.03 \\
\hline $\begin{array}{l}\text { H4: Perceived health-pro- } \\
\text { moting role model }\end{array}$ & $1.03(1.01-1.05)$ & 0.04 & $1.07(1.04-1.11)$ & $<0.01$ & $1.07(1.04-1.11)$ & $<0.01$ \\
\hline
\end{tabular}

Model 1 adjusted for nursing group (nursing informatics community vs. hospital nurses).

Model 2 adjusted for nursing group (nursing informatics community vs. hospital nurses), age, chronic illness and medication use, health care provider use of electronic health record.

aVariance explained: Cox\&Snell $R^{2}=0.29$; Nagelkerke $R^{2}=0.39$.

bariance explained: Cox\&Snell $R^{2}=0.33$; Nagelkerke $R^{2}=0.44$. 
Table 5 Odds Ratio ${ }^{\mathrm{a}}$ Estimates of Perceived Data Privacy and Security Protection by ePHR Use in Providers Use of Electronic Health Records Subgroup

\begin{tabular}{|c|c|c|c|c|c|c|}
\hline \multirow[t]{2}{*}{ H5 } & \multicolumn{3}{|c|}{ Providers do not use EHR $(n=250)$} & \multicolumn{3}{|c|}{$\begin{array}{l}\text { Providers use EHR } \\
(n=597)\end{array}$} \\
\hline & $\beta$ & OR $(95 \% \mathrm{Cl})$ & $p$ & $\beta$ & OR $(95 \% \mathrm{CI})$ & $p$ \\
\hline $\begin{array}{l}\text { PDPSP } \\
\text { (Crude odd ratios) }\end{array}$ & -0.04 & $0.96(0.92-1.00)$ & 0.06 & 0.01 & $1.01(0.99-1.04)$ & 0.29 \\
\hline $\begin{array}{l}\text { PDPSP } \\
\text { (Model 1) }\end{array}$ & -0.04 & $0.96(0.92-0.99)$ & 0.04 & 0.01 & $1.01(0.98-1.03)$ & 0.55 \\
\hline $\begin{array}{l}\text { PDPSP } \\
\text { (Model 2) }\end{array}$ & -0.05 & $0.95(0.91-0.99)$ & 0.03 & 0.01 & $1.01(0.98-1.03)$ & 0.72 \\
\hline
\end{tabular}

PDPSP=perceived data privacy and security protection, continuous total scale (higher score is better).

$E H R=$ electronic health record. $\beta=$ beta coefficient.

aSeparate odds ratios calculated for subgroups because of positive interactions.

Model 1 adjusted for nursing group (nursing informatics community vs. hospital nurses).

Model 2 adjusted for nursing group (nursing informatics community vs. hospital nurses), age, chronic illness and medication use.

Table 6 Odds Ratioa Estimates of Perceived Health-Promoting Role Model by ePHR Use in Age Subgroup

\begin{tabular}{|c|c|c|c|c|c|c|}
\hline \multirow[t]{2}{*}{ H5 } & \multicolumn{3}{|c|}{$\begin{array}{l}\text { Age }(\leq 50) \\
(n=498)\end{array}$} & \multicolumn{3}{|c|}{$\begin{array}{l}\text { Age }(>50) \\
(n=346)\end{array}$} \\
\hline & $\beta$ & OR $(95 \% \mathrm{Cl})$ & $p$ & $\beta$ & OR $(95 \% \mathrm{CI})$ & $p$ \\
\hline $\begin{array}{l}\text { PHPRM } \\
\text { (Crude odds ratios) }\end{array}$ & 0.01 & $1.01(0.98-1.04)$ & 0.62 & 0.06 & $1.07(1.02-1.11)$ & $<0.01$ \\
\hline $\begin{array}{l}\text { PHPRM } \\
\text { (Model 1) }\end{array}$ & -0.01 & $1.00(0.96-1.03)$ & 0.91 & 0.06 & $1.06(1.02-1.11)$ & 0.01 \\
\hline $\begin{array}{l}\text { PHPRM } \\
\text { (Model 2) }\end{array}$ & -0.01 & $0.99(0.96-1.03)$ & 0.64 & 0.05 & $1.05(1.01-1.10)$ & 0.02 \\
\hline
\end{tabular}

PHPRM=perceived health-promoting role model, continuous total scale (higher score is better). $\beta=$ beta coefficient. aseparate odds ratios calculated for subgroups because of positive interactions. Model 1 adjusted for nursing group (nursing informatics community vs. hospital nurses).

Model 2 adjusted for nursing group (nursing informatics community vs. hospital nurses), chronic illness and medication use, and health care providers use electronic health record. 


\section{References}

1. News: Secretary Sebelius announces next stage for providers adopting electronic health records [Internet]. U.S. Department of Health \& Human Services (DHHS); 2012 [updated 2014 Aug 25; cited 2014 Sep 27]. Available from: http://www.hhs.gov/news/press/2012pres/02/20120224a.html

2. Blumenthal D, Tavenner M. The "meaningful use" regulation for electronic health records. N Engl J Med 2010; 363(6): 501-504. doi:10.1056/NEJMp1006114.

3. Eligible hospital and critical access hospital meaningful use core measures measure 6 of 16 stage 2. Baltimore: Centers for Medicare \& Medicaid Services; 2014 [updated 2014 Aug; cited 2014 Aug 27]. Available from: http://www.cms.gov/Regulations-and-Guidance/Legislation/EHRIncentivePrograms/downloads/ Stage2_HospitalCore_6_PatientElectronicAccess.pdf

4. The national alliance for health information technology report to the office of the national coordinator for health information technology on defining key health information technology terms [Internet]. U.S. Department of Health and Human Services; 2008 [updated 2008 Apr 28; cited 2014 Sep 27]. Available from: http://www.nacua.org/documents/HealthInfoTechTerms.pdf

5. The role of the personal health record in the EHR (updated) [Internet]. American Health Information Management Association; 2010 [updated 2010 Nov; cited 2014 Sep 27]. Available from: http://library.ahima.org/xpedio/idcplg?IdcService=GET_HIGHLIGHT_INFO\&Query-

Text=\%28role+of +the+personal\%29\%3Cand\%3E\%28xPublishSite\%3Csubstring\%3E\%60BoK\%60\%29\&SortField=xPubDate\&SortOrder=Desc\&dDocName=bok1_048517\&HighlightType $=$ HtmlHighlight $\&$ dWebExtension $=$ hcsp

6. HIMSS personal health records definition and position statement [Internet]. Healthcare Information Management and Systems Society; 2007 [updated 2007 Sep 28; cited 2014 Sep 27]. Available from: http://himss.files.cms-plus.com/himssorg/content/files/phrdefinition071707.pdf

7. Tang PC, Ash JS, Bates DW, Overhage JM, Sands DZ. Personal health records: Definitions, benefits, and strategies for overcoming barriers to adoption. J Am Med Inform Assoc 2006; 13(2): 121-126. doi:10.1197/jamia.M2025.

8. Consumer health IT applications [Internet]. U.S. Department of Health \& Human Services; 2013 [updated 2013 Nov; cited 2014 Sep 27]. Available from: http://healthit.ahrq.gov/key-topics/consumer-health-it-applications\#six

9. Davis Giardina T, Menon S, Parrish DE, Sittig DF, Singh H. Patient access to medical records and healthcare outcomes: a systematic review. J Am Med Inform Assoc 2014; 21(4): 737-741. doi: 10.1136/amiajnl-2013-002239.

10. Kupchunas, WR. Personal health record: new opportunity for patient education. Orthop Nurs 2007; 26(3): 185-91; quiz 192-193.

11. Ant Ozok A, Wu H, Garrido M, Pronovost PJ, Gurses AP. Usability and perceived usefulness of personal health records for preventive health care: Patients' and primary care providers' perspectives. Appl Ergon 2014; 45(3): 613-628. doi:10.1016/j.apergo.2013.09.005.

12. Krist AH, Woolf SH, Rothemich SF, Johnson RE, Peele JE, Cunningham TD, Longo DR, Bello GA, Matzke GR. Interactive preventive health record to enhance delivery of recommended care: a randomized trial. Ann Fam Med 2012; 10(4): 312-319. doi:10.1370/afm.1383.

13. Nagykaldi Z, Aspy CB, Chou A, Mold JW. Impact of a Wellness Portal on the delivery of patient-centered preventive care. J Am Board Fam Med 2012; 25(2): 158-167. doi: 10.3122/jabfm.2012.02.110130.

14. Wright A, Poon EG, Wald J, Feblowitz J, Pang JE, Schnipper JL, Grant RW, Gandhi TK, Volk LA, Bloom A, Williams DH, Gardner K, Epstein M, Nelson L, Businger A, Li Q, Bates DW, Middleton B. Randomized controlled trial of health maintenance reminders provided directly to patients through an electronic PHR. J Gen Intern Med 2012; 27(1): 85-92. doi: 10.1007/s11606-011-1859-6.

15. Hibbard JH, Mahoney ER, Stockard J, Tusler M. Development and testing of a short form of the patient activation measure. Health Serv Res 2005; 40(6 Pt 1): 1918-1930. doi: 10.1111/j.1475-6773.2005.00438.x.

16. Archer N, Fevrier-Thomas U, Lokker C, McKibbon KA, Straus SE. Personal health records: A scoping review. J Am Med Inform Assoc 2011; 18(4): 515-522. doi:10.1136/amiajnl-2011-000105.

17. A community view on how personal health records can improve patient care and outcomes in many health care settings [Internet]. Northern Illinois Physicians for Connectivity (NIPFC) and Northern Illinois University Regional Development Institute (NIU RDI); 2009 [cited 2014 Sep 27]. Available from: http://www. mrccg.com/media/1627/personal_health_records_and_patient_care_2009.pdf

18. Kahn JS, Aulakh V, Bosworth A. What it takes: characteristics of the ideal personal health record. Health Aff (Millwood) 2009; 28(2): 369-376. doi: 10.1377/hlthaff.28.2.369. 
19. Fonda SJ, Kedziora RJ, Vigersky RA, Bursell SE. Combining iGoogle and personal health records to create a prototype personal health application for diabetes self-management. Telemed J E Health 2010; 16(4): 480-489. doi:10.1089/tmj.2009.0122.

20.Hess R, Bryce CL, Paone S, Fischer G, McTigue KM, Olshansky E, Zickmund S, Fitzgerald K, Siminerio L. Exploring challenges and potentials of personal health records in diabetes self-management: Implementation and initial assessment. Telemed J E Health 2007; 13(5): 509-517.

21.Grant RW, Wald JS, Schnipper JL, Gandhi TK, Poon EG, Orav EJ, Williams DH, Volk LA, Middleton B. Practice-linked online personal health records for type 2 diabetes mellitus: A randomized controlled trial. Arch Intern Med 2008; 168(16): 1776-1782. doi:10.1001/archinte.168.16.1776.

22. Tenforde M, Nowacki A, Jain A, Hickner J. The association between personal health record use and diabetes quality measures. J Gen Intern Med 2012; 27(4): 420-424. doi:10.1007/s11606-011-1889-0.

23. Lau M, Campbell H, Tang T, Thompson DJ, Elliott T. Impact of patient use of an online patient portal on diabetes outcomes. Can J Diabetes 2014; 38(1): 17-21. doi: 10.1016/j.jcjd.2013.10.005.

24.Zikmund-Fisher BJ, Exe NL, Witteman HO. Numeracy and literacy independently predict patients' ability to identify out-of-range test results. J Med Internet Res 2014; 16(8): e187. doi: 10.2196/jmir.3241.

25. Day K, Gu Y. Influencing factors for adopting personal health record (PHR). Stud Health Technol Inform 2012; 178: 39-44.

26. Cimino JJ, Patel VL, Kushniruk AW. The patient clinical information system (PatCIS): Technical solutions for and experience with giving patients access to their electronic medical records. Int J Med Inform 2002; 68(1-3): 113-127.

27. Mandl KD, Simons WW, Crawford WC, Abbett JM. Indivo: A personally controlled health record for health information exchange and communication. BMC Med Inform Decis Mak 2007; 7: 25. doi:10.1186/1472-6947-7-25.

28. Wagner PJ, Howard SM, Bentley DR, Seol YH, Sodomka P. Incorporating patient perspectives into the personal health record: Implications for care and caring. Perspect Health Inf Manag 2010; 7: 1e.

29. Yau GL, Williams AS, Brown JB. Family physicians' perspectives on personal health records: Qualitative study. Can Fam Physician 2011; 57(5): e178-e184.

30. Tang PC, Lansky D. The missing link: Bridging the patient-provider health information gap. Health Aff (Millwood) 2005; 24(5): 1290-1295. doi:10.1377/hlthaff.24.5.1290.

31. Hassol A, Walker JM, Kidder D, Rokita K, Young D, Pierdon S, Deitz D, Kuck S, Ortiz E. Patient experiences and attitudes about access to a patient electronic health care record and linked web messaging. J Am Med Inform Assoc 2004; 11(6): 505-513. doi:10.1197/jamia.M1593

32. Ralston JD, Carrell D, Reid R, Anderson M, Moran M, Hereford J. Patient web services integrated with a shared medical record: patient use and satisfaction. J Am Med Inform Assoc 2007; 14(6): 798-806.

33. Fuji KT, Galt KA, Serocca AB. Personal health record use by patients as perceived by ambulatory care physicians in Nebraska and south Dakota: A cross-sectional study. Perspect Health Inf Manag 2008; 5: 15.

34. Romano M, Gesualdo F, Pandolfi E, Tozzi AE, Ugazio AG. Use of the internet by Italian pediatricians: habits, impact on clinical practice and expectations. BMC Med Inform Decis Mak 2012; 12(23): 1-7. doi:10.1186/1472-6947-12-23.

35. Witry MJ, Doucette WR, Daly JM, Levy BT, Chrischilles EA. Family physician perceptions of personal health records. Perspect Health Inf Manag 2010; 7: 1d.

36. Wynia MK, Torres GW, Lemieux J. Many physicians are willing to use patients' electronic personal health records, but doctors differ by location, gender, and practice. Health Aff (Millwood) 2011; 30(2): 266-273. doi:10.1377/hlthaff.2010.0342.

37. Atkinson NL, Massett HA, Mylks C, Hanna B, Deering MJ, Hesse BW. User-centered research on breast cancer patient needs and preferences of an internet-based clinical trial matching system. J Med Internet Res 2007; 9(2): e13. doi:10.2196/jmir.9.2.e13.

38. Tracy CS, Dantas GC, Upshur RE. Feasibility of a patient decision aid regarding disclosure of personal health information: Qualitative evaluation of the health care information directive. BMC Med Inform Decis Mak 2004; 4:1 3. doi:10.1186/1472-6947-4-13.

39. Kahn JS, Hilton JF, Van Nunnery T, Leasure S, Bryant KM, Hare CB, Thom DH. Personal health records in a public hospital: Experience at the HIV/AIDS clinic at San Francisco general hospital. J Am Med Inform Assoc 2010; 17(2): 224-228. doi:10.1136/jamia.2009.000315.

40. Kim MI, Johnson KB. Patient entry of information: Evaluation of user interfaces. Journal of Medical Internet Research 2004; 6(2): e13. doi:10.2196/jmir.6.2.e13.

41.Lober WB, Zierler B, Herbaugh A, Shinstrom SE, Stolyar A, Kim EH, Kim Y. Barriers to the use of a personal health record by an elderly population. Proceedings of the Annual AMIA Symposium; 2006: $514-518$. 
42. Noblin AM, Wan TT, Fottler M. The impact of health literacy on a patient's decision to adopt a personal health record. Perspect Health Inf Manag 2012; 9: 1-13.

43. PHR adoption on the rise [Internet]. New York: Markle Foundation; 2011 [updated 2011 Jan 31; cited 2014 Sep 27]. Available from: http://www.markle.org/publications/1440-phr-adoption-rise

44. Thede L. Informatics: Electronic personal health records: Nursing's role. Online Journal of Issues in Nursing [Internet]. 2008 [cited 2014 Sep 29];14(1). doi:10.3912/OJIN.Vol14No1InfoCol01. Available from: http://www.nursingworld.org/MainMenuCategories/ThePracticeofProfessionalNursing/Health-IT/Elec tronic-Personal-Health-Records.html

45.Davis FD. Perceived usefulness, perceived ease of use, and user acceptance of information technology. MIS Quarterly 1989; 13(3): 319-340.

46. Holden R, Karsh B. The technology acceptance model: its past and its future in health care. J Biomed Inform 2010; 43(1): 159-172. doi:10.1016/j.jbi.2009.07.002.

47. Chismar WG, Wiley-Patton S. Does the extended technology acceptance model apply to physicians. Proceedings of the 36th Annual Hawaii International Conference on System Sciences (HICSS'03) - Track 6 Volume 6 (HICSS '03). Hawaii; 2003; IEEE Computer Society, Washington, DC, USA; 2003:160.

48. Dixon DR, Stewart M. Exploring information technology adoption by family physicians: Survey instrument valuation. Proceedings of the Annual AMIA Symposium; 2000: 185-189.

49. Liang H, Xue Y, Byrd TA. PDA usage in health care professionals: Testing an Extended technology acceptance model. Int J Mob Commun 2003; 1(4): 372-389. doi:10.1504/IJMC.2003.003992.

50. Paré G, Sicotte C, Jacques H. The effects of creating psychological ownership on physicians' acceptance of clinical information systems. J Am Med Inform Assoc 2006; 13(2): 197-205. doi:10.1197/jamia.M1930.

51.Van Schaik P, Bettany-Saltikov J, Warren JG. Clinical acceptance of a low-cost portable system for postural assessment. Behaviour \& Information Technology 2002; 21(1): 47-57. doi:10.1080/01449290110107236.

52. Schnall R, Bakken S. Testing the technology acceptance model: HIV case managers' intention to use a continuity of care record with context-specific links. Inform Health Soc Care 2011; 36(3): 161-172. doi: $10.3109 / 17538157.2011 .584998$.

53.Liu L, Ma Q. Perceived system performance: A test of an extended technology acceptance model. SIGMIS Database 2006; 37(2-3): 51-59. doi:10.1145/1161345.1161354.

54. Lu CH, Hsiao JL, Chen RF. Factors determining nurse acceptance of hospital information systems. Comput Inform Nurs 2012; 30(5): 257-264. doi:10.1097/NCN.0b013e318224b4cf.

55.Zhang H, Cocosila M, Archer N. Factors of adoption of mobile information technology by homecare nurses: A technology acceptance model 2 approach. Comput Inform Nurs 2010; 28(1): 49-56. doi:10.1097/NCN.0b013e3181c0474a.

56. Wu JH, Wang SC, Lin LM. Mobile computing acceptance factors in the health care industry: A structural equation model. Int J Med Inform 2007; 76(1): 66-77. doi:10.1016/j.ijmedinf.2006.06.006.

57.Rogers EM. Diffusion of innovations. 4th ed. New York: Free Press, 1995. 519p.

58. Moore GC. Benbasat I. Development of an instrument to measure the perceptions of adopting an information technology innovation. Information Systems Research 1991; 2(3): 192-222.

59. Consumers and health information technology: A national survey [Internet]. Oakland: California Health Care Foundation; 2010 [updated 2010 Apr; cited 2014 Sep 27]. Available from: http://www.chcf.org/ /media/MEDIA\%20LIBRARY\%20Files/PDF/C/PDF\%20ConsumersHealthInfoTechnologyNationalSurvey.pdf

60. Connolly MA, Gulanick M, Keough V, Holm K. Health practices of critical care nurses: Are these nurses good role models for patients? Am J Crit Care 1997; 6(4): 261-266.

61. Rush KL, Kee CC, Rice M. The self as role model in health promotion scale: development and testing. West J Nurs Res 2010; 32(6): 814-832. doi:10.1177/0193945910361595.

62.The U.S. nursing workforce: Trends in supply and education [Internet]. U.S. Department of Health and Human Services. Health Resources and Services Administration Bureau of Health Professions National Center for Health Workforce Analysis; 2013 [updated 2013 Apr; cited 2014 Sep 27]. Available from: http://bhpr.hrsa.gov/healthworkforce/reports/nursingworkforce/nursingworkforcefullreport.pdf

63. Kim E, Mayani A, Modi S, Kim Y, Soh C. Evaluation of patient-centered electronic health record to overcome digital divide. Conf Proc IEEE Eng Med Biol Soc 2005; 2: 1091-1094.

64. Just looking: consumer use of the internet to manage care [Internet]. Oakland: California Health Care Foundation; 2008 [updated 2008 May; cited 2014 Sep 27]. Available from: http://www.chcf.org/publi cations/2008/05/just-looking-consumer-use-of-the-internet-to-manage-care

65.Topline results from a National Consumer Survey on Health IT [Internet]. Oakland: California Health Care Foundation; 2010 [updated 2010 Apr; cited 2014 Sep 27]. Available from: http://www.chcf.org/ /media/MEDIA\%20LIBRARY\%20Files/PDF/T/PDF\%20ToplineResultsNationalConsumerSurveyHIT.pdf 
66. Patel VN, Abramson E, Edwards AM, Cheung MA, Dhopeshwarkar RV, Kaushal R. Consumer attitudes toward personal health records in a beacon community. Am J Manag Care 2011; 17(4): e104-e120.

67. The nationwide privacy and security framework for electronic exchange of individually identifiable health information [Internet]. U.S. Department of Health \& Human Services. Office of the National Coordinator for Health Information Technology; 2008 [updated 2008 Dec 15; cited 2014 Sep 27]. Available from: http://www.healthit.gov/sites/default/files/nationwide-ps-framework-5.pdf

68. Nunnally JO. Psychometric theory. 2nd ed. New York: McGraw-Hill, 1978. 701p.

69. Waltz CF, Strickland OL, Lenz ER. Measumrent in nursing and health research. 4th ed. New York: Springer Publishing Company, 2010. 492p.

70. Pallant J. SPSS Survival Manual. 3rd ed. London: Open University Press, 2007. 335p.

71.Duyck P, Pynoo B, Devolder P, Voet T, Adang L, Vercruysse J. User acceptance of a picture archiving and communication system. Applying the unified theory of acceptance and use of technology in a radiological setting. Methods Inf Med 2008; 47(2): 149-156.

72. Yi MY, Jackson JD, Park JS, Probst JC. Understanding information technology acceptance by individual professionals: Toward an integrative view. Information \& Management 2006; 43(3): 350-363. doi:10.1016/j.im.2005.08.006.

73. Day K, Gu Y. Influencing factors for adopting personal health record (PHR). Stud Health Technol Inform 2012; 178: 39-44.

74. Silvestre AL, Sue VM, Allen JY. If you build it, will they come? The Kaiser Permanente model of online health care. Health Aff (Millwood) 2009; 28(2): 334-344. doi:10.1377/hlthaff.28.2.334.

75. Kannan SB. Safety net providers bring patients online: lessons from early adopters. Oakland: California Health Care Foundation.; 2009 [updated 2009 Apr; cited 2015 Jan 1]. Available from: http://www.chcf. org/ /media/MEDIA\%20LIBRARY\%20Files/PDF/S/PDF\%20SafetyNetPatientsOnline.pdf

76. Schaper LK, Pervan GP. ICT and OTs: A model of information and communication technology acceptance and utilisation by occupational therapists. Int J Med Inform 2007; 76 (Suppl. 1): S212-S221. doi:10.1016/j.ijmedinf.2006.05.028.

77. Tung FC, Chang SC, Chou CM. An extension of trust and TAM model with IDT in the adoption of the electronic logistics information system in HIS in the medical industry. Int J Med Inform 2008; 77(5): 324-335. doi:10.1016/j.ijmedinf.2007.06.006.

78. Angst CM, Agarwal R. Adoption of electronic health records in the presence of privacy concerns: The elaboration likelihood model and individual persuasion. MIS Quarterly 2009; 33(2): 339-370.

79. Gagnon MP, Desmartis M, Labrecque M, Légaré F, Lamothe L, Fortin JP, Rancourt JF, Duplantie J. Implementation of an electronic medical record in family practice: A case study. Inform Prim Care 2010; 18(1): $31-40$.

80.Strobl JF, Latter S. Qualified nurse smokers' attitudes towards a hospital smoking ban and its influence on their smoking behavior. J Adv Nurs 1998; 27(1): 179-188.

81. Kelley K, Abraham C. Health promotion for people aged over 65 years in hospitals: Nurses' perceptions about their role. J Clin Nurs 2007; 16(3): 569-579.

82. Ash JS, Stavri PZ, Dykstra R, Fournier L. Implementing computerized physician order entry: The importance of special people. Int J Med Inform 2003; 69(2-3): 235-250.

83. Courtney KL, Alexander GL, Demiris G. Information technology from novice to expert: Implementation implications. J Nurs Manag 2008; 16(6): 692-699. doi:10.1111/j.1365-2834.2007.00829.x.

84. Hsiao JL, Chang HC, Chen RF. A study of factors affecting acceptance of hospital information systems: A nursing perspective. J Nurs Res 2011; 19(2): 150-160. doi:10.1097/JNR.0b013e31821cbb25.

85. Karsh BT, Escoto KH, Beasley JW, Holden RJ. Toward a theoretical approach to medical error reporting system research and design. Appl Ergon 2006; 37(3): 283-295. doi:10.1016/j.apergo.2005.07.003.

86. ONC consumer campaign pledge. Silver Spring: American Nurses Association, Inc.; 2014 [cited 2014 Sep 27]. Available from: http://www.nursingworld.org/MainMenuCategories/ThePracticeofProfessionalNurs ing/Health-IT/ONC-Consumer-Campaign-Pledge.html?css=print

87. Kaelber DC, Jha AK, Johnston D, Middleton B, Bates DW. A research agenda for personal health records (PHRs). J Am Med Inform Assoc 2008; 15(6): 729-736. doi:10.1197/jamia.M2547

88. Fisher B, Bhavnani V, Winfield M. How patients use access to their full health records: a qualitative study of patients in general practice. J R Soc Med 2009; 102(12): 539-544. doi:10.1258/jrsm.2009.090328.

89. Jamoom E, Beatty P, Bercovitz A, Woodwell D, Palso K, Rechtsteiner E. Physician adoption of electronic health record systems: United States, 2011 [Internet]. U.S. Department of Health and Human Services. NCHS data Brief, no 98, July 2012; 2012 [updated 2013 Jan 11; cited 2014 Sep 27]. Available from: http://www.cdc.gov/nchs/data/databriefs/db98.pdf

90. Masys D, Baker D, Butros A, Cowles KE. Giving patients access to their medical records via the internet: The PCASSO experience. J Am Med Inform Assoc 2002; 9(2): 181-191. 
91. Venkatesh V, Morris MG, Davis GB, Davis FD. User acceptance of information technology: Toward a unified view. MIS Quarterly 2003; 27(3): 425-478.

92. Rothman KJ, Greenland S. Public health matters. Causation and causal inference in epidemiology. Am J Public Health 2005; 95: S144-S150.

93. Venkatesh V, Davis FD. A theoretical extension of the technology acceptance model: Four longitudinal field studies. Management Science 2000; 46(2): 186-204. 